\title{
Analysis on E-Commerce Site Business Model
}

\author{
Ying Zhang ${ }^{1}$, Chenfeng Ma ${ }^{1}$, Jianing Zhang ${ }^{1}$, \\ Lu Cao $^{1}$, Yefei Yuan ${ }^{2}$ \\ ${ }^{1}$ Hainan University, Haikou, Hainan, 570228 \\ ${ }^{2}$ Chongqing University of Technology, Chongqing, 400054
}

KEYWORDS: E-Commerce, Site Business Model

\begin{abstract}
Development of electronic commerce is gradually affecting business operations, paper studies through e-commerce site operators to establish innovative business website system, adjust management, formation of enterprise information systems link, promote enterprise departments work closely together through the overall image marketing, change marketing expert for business-man combat team of marketing, enhance corporate image, marketing ability and operational efficiency, promote enterprise development.
\end{abstract}

\section{Introduction}

At present, the existing e-commerce site for SMEs can only play the role of mere propaganda, cannot become a corporate bond cannot be formed together with SMEs to create benefits for enterprises. Alibaba, Dangdang, Amazon, Taobao are very successful, but their business model is different: Alibaba B2B, Dangdang/Amazon B2C, Taobao of C2C, which are characterized by sales of goods or business of such operations. The mode corresponds to the enterprise to increase a department - the department of e-commerce. It can help enterprises to increase product sales, but cannot improve the overall operating efficiency of enterprises.

The current business is run with the team. E-commerce website as a tool for information systems must be able to become a corporate bond, the various departments within the enterprise linked internally to improve business efficiency and improve the company's image in the outside. And business managers can support the site, adjust the direction of the operation of enterprises, and promote the development of enterprises.

\section{The Related Definitions of E-Commerce}

E-commerce is technically, economically highly developed modern society, access to information technology and the rules of business, the systematic use of electronic tools, high efficiency and low cost in the general commodity exchange as the center of activities. This analysis highlights the full environmental, practitioners, the purpose of which e-commerce and standards.

Broadly speaking, E-commerce refers collectively to the electronic device as a medium for business activities; from the narrow sense, refers to the computer-based network carried out a variety of business activities, including providers of goods and services, advertising sum, consumers, intermediaries and other parties concerned to act. Report e-commerce refers to the narrow sense. 
Depending on the relationship between marketing, e-commerce can be divided into three types:

BtoB (Business to Business), refers to the supply and demand sides of e-commerce transactions are business (or business, the company), she (he) have used a variety of techniques or business networking Internet platform, completing the process of business transaction. E-commerce is a modern B2Bmarketing specific major manifestation.

BtoC (Business to Consumer), refers to the e-commerce business unit level with consumers, specifically refers to the realization of trading activity or enterprise businesses and consumers by way of the Internet, etc., it is also directly involved in consumer use of the network one form of economic activity. Also in this study based on e-commerce model is mainly involved.

CtoC (Consumer to Consumer), e-commerce refers to the individual and between individuals. For example, a consumer has used a mobile phone for transactions over networks, sell it to another person, this type of transaction is called C2C e-commerce.

\section{The Existing E-Commerce Site's Business Model}

The company has the personnel, business, production, technology, quality assurance, storage, finance and other departments, but also set up a website maintenance by IT companies, the company dedicated 'staff and a server for the company Web site and e-mail file servers, systems management, product management, order management, membership management, information management, human resources management, traffic statistics of the department can operate the site. The company for enterprises to bring order through the site improves customer relationships, processes, improve enterprise efficiency. Ministry of Commerce issued but only corporate product information, the Ministry of Personnel job information, other departments basically do not use.

The disadvantage of this site: First, the system is more complex database systems, cannot become the department of information communication link, the link between small departments, participation decreases. Second, the system is maintained and updated by the IT staff, heavy workload, requires a lot of 'staff. The third is a static site, visit the Web site is a passive, if not advertise, basically no browsing. Furthermore, the content of the website for SMEs are usually less, there is less opportunity to be viewed commercial access to nature is not high. The fourth is poor security.

\section{The Innovative E-Commerce Website and Its Business Model}

This site and warehouse system database systems are installed on enterprise servers, two systems are relatively independent, middle setting transit procedures, transit procedures and security with data conversion and filtering, can be connected to the subsequent banking system.

E-commerce website has become a display and user interface, a database for storing data page basis, all information processing and storage are carried out within the database system, in addition to the system administrator can update and maintain other operations are operations on the page and implementation of the program through the transit warehouse database called to put an end to foreign violated. Even if the hysteresis phenomenon, since the amount of data for SMEs is not in the same server to accept transit time lag, can ensure the safety of the warehouse database system between the two. Because of lower costs, and to solve the problem of shortage of funds for SMEs, IT companies their only regular maintenance and emergency repair assistance administrator, reducing dependency on IT companies. 
Adjust interface content, so that all departments in the above operation, the operator interface consists of systems, products, orders, customers, news, personnel, purchasing, storage, finance, technology, quality assurance management, information dissemination and other components.

(1) System Management. By the MIS (Management Information System) department is responsible, Function: Setting permissions, system management.

(2) Product Management. By the sales and technical management features: new product launches, to establish and maintain a list of materials and structure.

(3) Order management system. Maintained by the business and production sector, Function: order confirmation, order information publishing, production schedule, information feedback.

(4) Customer management systems. It is maintained by the commercial and financial sectors. Functions: customer information maintenance.

(5) Information management system. Commerce department maintenance, Function: Information Release.

(6) Personnel Management System. It is maintained by the personnel department, Function: Human Resources Management.

(7) Procurement management system. It is maintained by the purchasing department, Function: vendor management.

(8) Warehouse Management System. It is maintained by the warehouse department, Function: warehouse management.

(9) Financial management system. Maintenance by the finance department, function: financial data.

(10) The technology, quality assurance management system. It is maintained by the quality assurance and technical departments, functions: information management technology and quality assurance.

(11) The information distribution system. Each department co-management functions: information dissemination and management.

Through the above interface departments operator can input various information databases, and can query the required information, and information on the department's website database can be placed for new customers and suppliers about the company and products and browse parts information. For example, the purchasing department can be found on the website to the new order information, and vendor information, product price, delivery information and product quality information to facilitate the review of unusual problems with suppliers and delivery quality, price and so on.

Adjust the database system for the warehouse database system, enabling the system to complete the storage, query, management and other functions, and with automatic feedback feature.

(1) The basic database. With customers, orders, products, suppliers, employees and other data tables and associated information, inquiry and management functions. Information entered by the user interface can be automatically stored in the corresponding data table, and the formation of the data stream. For example, when the technology sector will be associated with the product information into the system, and the product is formed between the parts structure, production departments can understand the product's parts list, the business department can issue quotes to customers under the product structure.

(2) The automatic feedback system. When the system is built on the site, the program is set, the set range of values, the system automatically executes instructions, automatic detection information for each input, information input is greater than or less than the value, an automatic feedback system will form a data information corresponding to the information sent to the recipient, forming 
an automatic feedback system, and the information can be set as required without any feedback or tracking and feedback.

Enterprise MIS teams split up, in addition to system maintenance members, the other members shall be distributed to the various departments. Director responsible for maintaining the system, hardware and process improvements and training department heads composed of key user groups, to participate in the pre-planning, follow-up test run. To each sector operators (such as business, technical staff) set up an account, assign permissions. This not only reduces the labor cost of inputs to ensure that the 'stability and responsibility of members, but also for employees to provide training opportunities, so that they have a sense of belonging, thereby enhancing operational efficiency.

Homogenous goods on the market the large and high advertising costs, the effect is not good, especially in the marketing of many e-commerce sites in the environment how can you stand it?

Innovative e-commerce website business model introduced overall image marketing. In addition to the corporate image and product packaging, and more importantly, through the support e-commerce site for customers to display every detail of the production, such as development, production, delivery and quality, so that customers feel that each sector enterprises as customers service is very attentive, in order to achieve the purpose of marketing. By supporting e-commerce site, the overall image marketing by the following components:

(1) Adoption of the website system, the enterprise's information by e-mail the form to the customer, to allow customers to keep abreast of the dynamic enterprise.

(2) The system through the website, the customer automatically aggregate product information sent to the customer.

(3) The system through the website, the abnormality information automatically sent to the customer and improving program for customer decision.

(4) Through the website system, automatically send shipment information to customers.

(5) Establishment of customer accounts on the site system, customers can account for product information.

(6) The system set up by the technical quality of the website forum for customer feedback quality information and timely feedback and improvement.

Through this system, so that e-commerce site into a dynamic site, but also allows guests can always understand the dynamics of business and products. Furthermore, since the system is automatic website feedback system that lets customers feel the company is not a person (owner or business people) for his services, but the whole business team (in all sectors of business cooperation) in his service. Therefore, when an innovative e-commerce website after the successful operation, the company's marketing experts are no longer fighting alone, but the whole business of marketing team (sales, production, technology, quality control, etc.), this team enables customers to rest assured that the product to the operation of enterprises, and enterprises to introduce new customers, and customers through the customer presentation is generally relatively high-quality customer (integrity and high success rate). As e-commerce sites with automatically send information systems, in addition to maintaining existing customers outside, we can send the latest information on the company's system of new customers, give full play to advertising.

\section{The Impact of Innovative E-Commerce Site Operation Mode on the Enterprise}

First, through the website system support, sales and marketing initiative can be implemented in conjunction overall image marketing, improve product sales. Second, the support system through the website, the purchasing department can offer Post request for others, change from passive to 
active, and keep abreast of the status of delivery, and to understand each vendor quality problems abnormal parts, and requiring manufacturers to improve and enhance the quality of purchase. Third, after obtaining orders and for availability of information, facilitate the production department for production scheduling, so as to achieve lean production and inventory management model. Fourth, through the website system support, technical and quality control departments can produce anomalies in time and saves the exception and improve their programs into the system for production, purchasing and other departments queries and improved to IOS9000 requirements, produce abnormal improvement and processing method to query and traceability, to ensure continuous improvement in the next batch. Fifth, the financial sector can easily cope with various amounts, determined in accordance with the book production planning and quality assurance

department and its own system of disbursements, so as to enhance the financial credibility of enterprises.

\section{Conclusion}

Enterprises with operating flexibility, adaptability and strong market competitive advantage, and by supporting innovative e-commerce sites, in addition to enterprise customers through the website to learn, to understand the progress and development of enterprises outside the order, the department can also learn information, schedule tasks , different departments work closely together to enhance the overall efficiency; data managers can be provided through the system to develop marketing strategies and development plans to enable enterprises to board a new level.

\section{Reference:}

[1] Statistics Korea. E-commerce and Cyber Shopping Survey in 2012 and in the Fourth Quarter of 2012. 2013.

[2] David Meeman Scott. The New Rules of Marketing and PR [M]. John Wiley \& Sons, Inc. 2011.

[3] Kaplan Andreas, M. Michael Haenlein "Users of the World Unite The Challenges and Opportunities of Social Media" [J]. Business Horizons.2013. 